
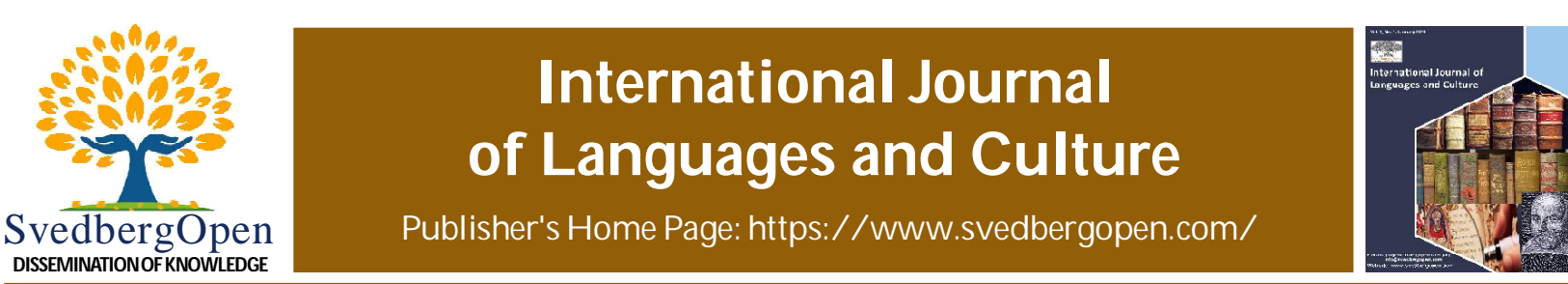

\title{
Language skills development in English through an integrated approach: The case of integrated skill instructions
}

Jean Paul Gaindjoung ${ }^{1 *}$

${ }^{1}$ Independent, University of Yaounde 1, Yaounde Ngoa-Ekelle, Yaounde, Centre 237, Cameroon. E-mail: gaindjoungjeanp@gmail.com

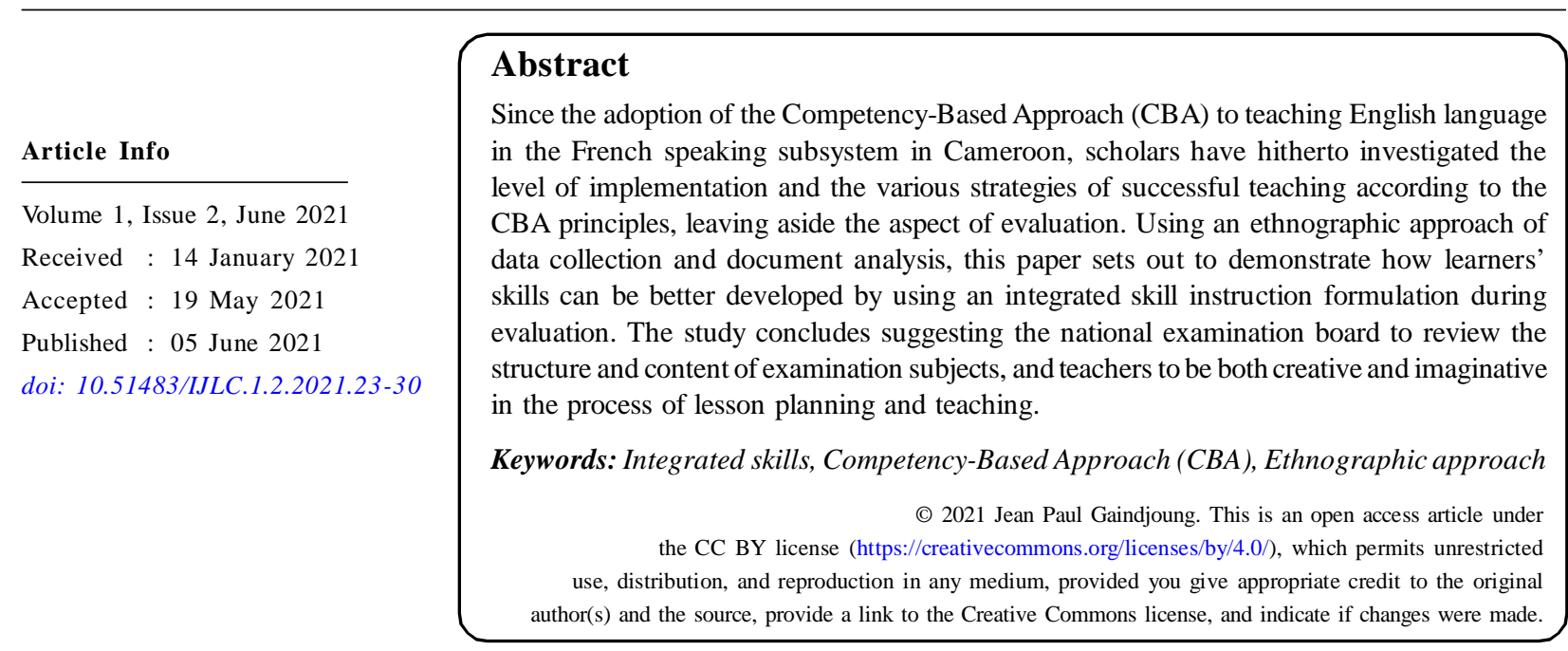

\section{Introduction}

It is commonly said in French among students in Cameroon that "C'est Dieu qui donne l'anglais". In other words, mastering English language is a divine gift. This is to show how difficult and even mysterious, learners perceive English. Such a claim is not haphazard; it is instead the result of several factors ${ }^{1}$ combined: the teaching-learning environment which is not sufficiently equipped to carry out certain activities (we allude to language laboratories, audio and video material), the textbooks ${ }^{2}$ that do not fit the overall socio-educative context, and the teaching method, which although has of recent been revised, many teachers have not integrated yet the wide range of possibilities that new approach labeled Competency-Based Approach (CBA), offers them to innovate at least in the classrooms before reaching the various national examination boards that are stuck on the old fashion, and the evaluation process which is in disruption with the syllabus (be it during continuous assessments or summative evaluations, aspects of language such as speaking and listening are not evaluated). As a matter of facts, evaluation enables to measure or verify whether the expected outcome set earlier has been met. This paper contends that instructions during evaluations have to be skill-integrated. After a brief recall of what the CBA is all about, we are going to summarize the recent literature on the CBA in Cameroon, indicate the methodology used in this work, then discuss how the integrated approach can enhance language skills development

Among those factors, we do not forget salaries which can play an incentive role.

It has been observed that textbooks are always selected with reference to elite schools in urban areas to the detriment of remote regions that obviously have distinct realties.

\footnotetext{
* Corresponding author: Jean Paul Gaindjoung, Independent, University of Yaounde 1, Yaounde Ngoa-Ekelle, Yaounde, Centre 237, Cameroon. E-mail: gaindjoungjeanp@gmail.com
} 
in the organization of lessons, finally, we are going to suggest ways of formulating instructions in an integrated approach perspective.

\section{Competency-Based Language Teaching (CBLT)/CBA}

The CBLT emerged in the USA in the 1970s as an application of the principles of Competency-Based Education. Unlike other language teaching approaches, the CBLT focuses on the outcome of learning, that is, what learners are expected to do with the language. It lays great emphasis on the functional and interactional perspectives. The CBLT seeks to teach language in relation to social contexts where it is used. It begins with a description of essential skills, knowledge, attitude and behavior required to achieve effective performance.

Eight-key features characterize the implementation of the CBLT, according to Auerbach (1986):

1. Successful functioning in society: Enable the learners to cope with the challenges of the world;

2. Life skills: Learners are drilled into language resources required in specific contexts;

3. Task or performance-centered orientation: The ultimate goal of teaching is what the learners can achieve with language.

4. Modularized instruction: Instruction is organized around modules (main objectives), which are segmented into units (sub-objectives) to make both teachers-learners have an idea of progress and know where they are heading to.

5. Outcomes are explicitly stated: They are mentioned in terms of behavioral expectation from learners;

6. Continuous and ongoing assessment: Learning achievements is assessed through quantifiable test results;

7. Demonstrated mastery of performance objectives: Unlike the traditional paper-and-pencil test, evaluation is based on the ability to demonstrate pre-specified behaviors;

8. Student-centered instruction: Teachers are mere guides. Instruction is not time-based; learners progress at their own pace, concentrating on abilities for which they lack competence.

The CBA came into implementation in secondary schools of Cameroon during the academic year 2014/2015. As indicated above, this approach of language teaching focuses on competence. If admitted that effective communication implies various interwoven skills and resources to be mobilized, it is obvious that integrated approach to teaching English will enhance or boost the learners' ability to use language in real-life situations. In other words, we consider the CBA as a major approach, then the integrated approach as a technique. Therefore, how can that be concretely done?

In Cameroon, in Higher Teachers' Training Colleges, student teachers are prepared to teach segregated language skills. That is, to isolate each specific skill or resource into a single lesson. Thus, on the field, skills such as reading and speaking are taught separately. For instance, a grammar lesson, will often be constructed around corpus sentences with no relationship neither with one another nor with the theme of the Unit. In this approach, language learning is separate from content learning, as observed Mohan (1986). What matters in such circumstances is the linguistic competence, but not the performance. As a result, learners would end up mastering grammatical rules, but failing to fluently communicate in real-life situations.

However, if admitted that, language skills and resources are interwoven; for instance, one cannot develop a successful speaking skill without sharpening the listening ability. Furthermore, the speech will be sensible if the vocabulary is accurate and the syntax is structured. Finally, the speech will be understandable if the pronunciation is good. Therefore, teaching English language to successfully develop language skills requires to combine or better still to integrate different skills or resources in a single lesson. In this perspective, we may have reading/grammar, speaking/vocabulary, reading/writing, etc. depending on the teacher's creativity. For example, regarding a reading/writing class for secondary school learners, the teacher may use a piece of text about the biography of a famous star, to teach learners how to write a biography. The before-reading questions will require learners to develop both their listening and speaking abilities. Students might be asked afterwards to gather, organize themselves and produce their own text, thus developing their writing skills. Similarly, for a reading/writing lesson, the teacher may probably give all of the directions orally in English, thus causing students to use their listening ability to understand the assignment. In this course, students might discuss their readings, thus employing speaking and listening skills and certain associated skills, such as pronunciation, syntax, and social usage. Students might be asked to summarize or analyze readings in written form, thus activating their writing skills. In a real sense, then, some courses that are labeled according to one specific skill might actually reflect an integrated-skill approach after all. 


\section{The CBA in Cameroon}

The current decade has witnessed a good number of contributions aiming at improving the quality of English language teaching in Cameroon.

Gardner (2012), from the onset, castigates the teaching methods in many African countries which according to him, are based on the colonial French or British model. Chiatoh and Akumbu (2014) in the perspective of going back to roots, uphold that sustainable English language studies can be better achieved by using culturally rooted methods in which Cameroonians can identify themselves, and by adopting national languages as medium of instruction.

In contrast, Fontem and Oyetade (2005) are for the decongestion of classrooms and the increase of the number of teachers trained, in order to balance the student-teacher ratio. Agbor (2019) also insists on the in state universities to train and graduate students ready to teach specific English language domains.

Despite the introduction of the CBA in French subsystem, some scholars still observe that the teaching method has not changed indeed. Nkwetisama (2012) for instance points out that English language teaching in Cameroon is more about the teacher, the textbook and chalk. He then proposes the process and activities to carry out in order to develop learners' know-how and ends with a typical CBA lesson plan. Similarly, Nforbi and Siewoue (2015), in an assessment of the application of the CBA by teachers in the Menoua Division, reveal that the majority of teachers $(63,64 \%)$ find the new method difficult to understand. Likewise, Njwe (2016) bitterly concludes that $93,4 \%$ of teachers are aware of the paradigm shift, but only $17,6 \%$ assert to understand what the CBA entails, and merely $25,7 \%$ of teachers feel ready to implement it.

Aware also of the failure of the implementation of the CBA, Nkemleke and Belibi (2019) propose five language teaching strategies to reverse the tendency:

1. A relaxed classroom environment; that is, a conducive environment to learning, with songs, games, dramatization, etc.

2. Learner centeredness; focus on the student as the center of learning.

3. Communication-oriented classroom. The teacher shall initiate talk, students respond and the teacher provides feedback.

4. Visual scaffolding. It is "an approach in which the language used in instruction is made more understandable by the display of drawings or photographs that allow students to hear English words.” (Herrell and Jordan, 2012)

5. Authentic materials; that is, material produced in order to communicate rather than to teach. For instance movies, songs, telephone messages, etc.

From the foregoing, it goes without saying that a lot has been said and proposed about strategies of implementing effectively and efficiently the CBA in classrooms; yet none of these previous publications have explored the aspect of evaluation. Teaching is one thing, but evaluating is quite different. Evaluation is the only arena where the skills and competencies can be actually assessed, whereof the necessity for appropriate instruction formulation.

\section{Methodology}

The data of this study were collected following an ethnographic approach. As a reminder, Mahboob et al. (2016) clarify that:

Ethnographic research involves the direct observation of human behavior within particular settings and seeks to understand a social reality from the perspectives of those involved. [...] Researchers are encouraged to immerse themselves in the everyday activities of the group of people whose meaning-making practices (also known as emic or insider perspectives) they are attempting to understand.

The author has been teaching English and French for more than eight years now. The data have been collected from continuous assessment examination papers of French speaking schools in Yaounde and official BEPC English examination papers. The sample papers in question are pasted in the appendices. In this process, attention has been paid on the formulation of instructions.

As for the analysis, documentary analysis has been used to assess the extent to which instructions on evaluation papers allow candidates to display what they are able are capable of doing with language resources and skills acquired.

\section{Integrated skill instruction}

As you teach, so shall you assess. The CBLT in force in the education system of Cameroon focuses on what learners are able to do with language. Unfortunately, instructions and directions on evaluation papers do not reflect this policy. 
They generally tackle a specific skill or resource, and merely portray the various life-situations provided by the national syllabus. Furthermore, some instructions though appealing to a combination of resources, do not contain context clues that could enable the candidate to figure out the real-life situation evoked in the exercise. Below is an illustration from one of the most recent national examination paper.

Looking at the instructions appearing in the above examination paper, it is obvious that they do not enable the candidates to actually demonstrate what they are capable to do with language, nor how they can cope with certain reallife situations. In this examination paper, the candidates are being evaluated on their knowledge about the language and not their knowledge of what they can do with language. It is one thing to master the structure of a language, but it quite a different thing to make use of these structures accurately.
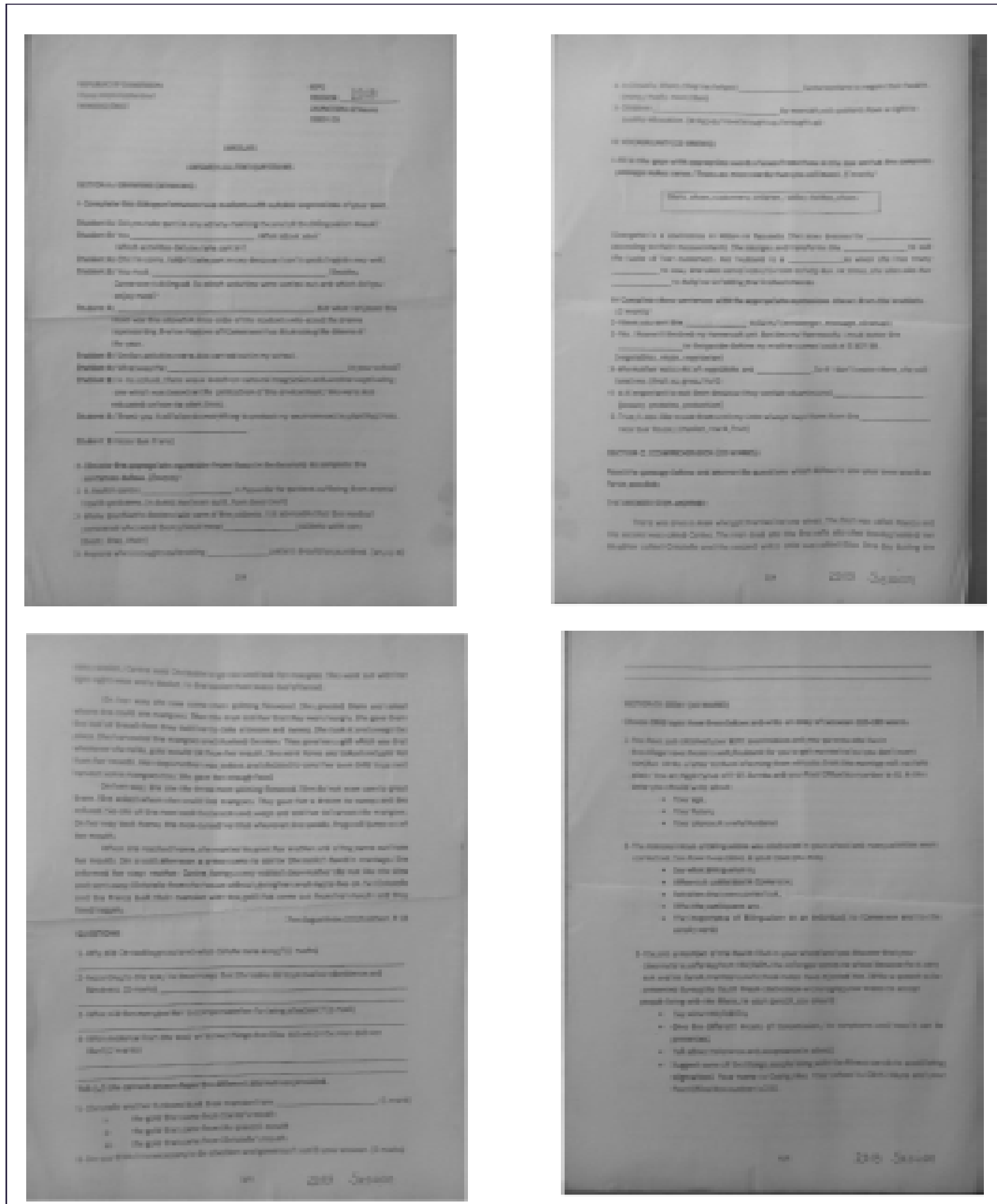
Furthermore, skills evaluated are segregated in contrast with the requirement of the CBA. The various recommendations from national inspectors, such as labeling the competence over which the candidates are being evaluated is not respected, neither is mentioned the real-life situation in question for each exercise. Finally, there are no guidelines for the essay writing topics. So, decision makers say one thing, but act differently and such a situation embarrasses those teachers who systematically apply the recommendations, and also those learners who are left in total confusion. Thus, how can instructions be well labeled?

There are actually two major types of integrated-skill instruction: content-based language instruction; and task-based instruction. The first lays emphasis on learning content through language, while the second stresses on doing tasks that require communicative language use. Both of these benefits from a diverse range of materials that may be textbooks, and audio-visual tools.

In content-based instruction, students practice all the language skills in a highly integrated, communicative fashion while learning content such as science, mathematics, and social studies. Content-based language instruction is valuable at all levels of proficiency, but the nature of the content might differ by proficiency level. For beginners, the content may involve basic social and interpersonal communication skills, but as we move upwards, the content can become increasingly academic and complex. At least three general models of content-based language instruction exist: theme-based, adjunct, and sheltered (Scarcella and Oxford, 1992). The theme-based model integrates the language skills into the study of a theme, as it is done in textbooks, but unfortunately neglected during summative evaluations (e.g., juvenile delinquency, cross-cultural differences in marriage practices, climate change, and citizenship). The theme must be very interesting to students and must allow a wide variety of language skills to be practiced, always in the service of communicating about the theme. A tentative instruction in this perspective for 3ème classes could be:

\section{“Using your knowledge about good practices in society, complete this cloze text with appropriate words so as to make sense".}

The above instruction has two major advantages: first of all, it makes reference to a general topic of citizenship contained in the syllabus. Secondly, it prepares the candidate to foresee the jargon that must be mobilized in order to solve the task.

In the adjunct model, language and content courses are taught separately but are carefully coordinated. In the sheltered model, the subject matter is taught in simplified English tailored to students' English proficiency level.

“Task-Based Instruction.” In task-based instruction, students participate in communicative tasks in English. Tasks are defined as activities that can stand alone as fundamental units and that require comprehending, producing, manipulating, or interacting in authentic language while attention is principally paid to meaning rather than form (Nunan, 1989). This can be done as a project at the end of a unit or a module, in such a way that each learner showcases his/her practical knowledge. It effectively gives room for personal work as far as language is concerned, and creativity in terms of know-how. This can be better applied in end-of-year examinations at the level of "Essay Writing" in the following way:

- Name a recyclable object and describe step by step how to recycle it.

- Draw a national emblem; then, in three lines, describe it.

- What is your favorite crop? How is it grown?

The above instructions have the advantage of combining linguistic competence and practical know-how, that is, handicraft and writing, drawing and writing, farming and writing). In task-based instruction, basic pair work and group work are often used to increase student interaction and collaboration. For instance, students work together to write and edit a class newspaper, recycle waste material, play roles, or create a school garden. More structured cooperative learning formats can also be used in task-based instruction. Task-based instruction is relevant to all levels of language proficiency, but the nature of the task varies from one level to the other. Tasks become increasingly complex at higher proficiency levels. For instance, beginners might be asked to introduce each other and share one item of information about each other in 6eme and 5eme classes..

By so doing, learners are no longer annoyed with repeated grammar and vocabulary lessons separated from a major theme. More so, learners being interested in the tasks or content find themselves learning and making much effort than ever before. However, for this to be systematically implemented, educationists must depart from the old evaluation style wherein language structure is the main focus, and skills are separately evaluated. The evaluation must be driven towards what learners can actually do with language, in such a way that all the skills and resources will be mobilized to meet the goal. 
From this observation, educationists as well as national pedagogic inspectors have each at their respective duty, to rethink and revise the way learners must be henceforth be evaluated according to the CBA perspective. It is obvious that if proper evaluation is achieved in classrooms but not perpetuated in official exams, there will still remain a serious problem, given that the learners' ultimate goal in examination classes is to successfully perform at the end-of-year examinations.

\section{Conclusion}

The ultimate goal for learning a language is to communicate effectively. Given that the previous approach to teaching English to French-speaking students in Cameroon was proven ineffective, the government has adopted a new method labeled Competency-Based, which aims at correcting the limitations of the previous method. Previous investigations have proven that teachers are aware of the necessity for a paradigm shift, though very few do understand what the CBA is all about, while a striking majority is not ready to join the new trend. The situation gets worse when it comes to evaluating learners. Instructions in examination papers are not competence-driven. To remedy this old practice, we have suggested two types of instructions: content-based instructions and task-based instructions, according to the expected outcome and the level of learners. Finally, we formulate the following suggestions towards educationists concerned with the CBA: While preparing their lessons, teachers must henceforth think about the following:

- Look for various ways to integrate language skills in the lessons and evaluations (e.g., content-based, task-based, or a combination).

- Always make a self-assessment of their current approach and evaluate the extent to which the skills are integrated. That is, a continuous questioning of the teaching method and goals.

- Make use of instructional materials at their disposal: textbooks, and technologies that promote the integration of listening, reading, speaking, and writing, as well as the associated skills of syntax, vocabulary, and so on. Beyond everything, teachers must be creative enough.

- Even if a given course is labeled according to just one skill, remember that it is possible to integrate the other language skills through appropriate tasks.

If these parameters are respected; teaching English will no longer be monotonous and boring as it used to be. The teachers will guide learners according to their needs and their environment. Finally, the ultimate outcome will easily be met.

However, for examination classes where the main objective of learners is to pass the final year exam, the government body in charge of organizing examinations must also update the quality of examination papers to suit the national syllabus. Otherwise, learners may end up achieving successful communication but not performing well at the examination, given that so far, examination questions are oriented towards the mastery of language structures only.

\section{References}

Agbor, T.N. (2019). Professionalising English Language Teaching in Cameroon; Challenges and Prospects in some Engineering Higher Institutes of Learning in Yaounde. Lambert Academic Publishing, Yaounde.

Auerbach, E.R. (1986). Competency-based ESL: One step forward or two steps back? TESOL. Quarterly. 20(3), 411-415

Belibi, E. P. R. (2018). Competency-based English language teaching in Cameroon francophone secondary schools: Peculiarities, challenges and solutions. in L.N. Afutendem, C.M. Nkwetisama and G. T. Fai (Eds.). Language and Literature Sciences in Contemporary Cameroon and the Commonwealth. 99-126.

Bloomfield, L. (1933). Language. New York: Henry Holt.

Brown, H.D. (2001). Teaching by Principles: An Interactive Approach to Language Pedagogy. 2nd Edution. New York: Pearson Education.

Chiatoh, B.A. and Akumbu, P.W. (2014). Enhancing English language studies in Cameroon: the mother tongue perspective. in California Linguistic Notes, 39(1).

Fontem, A.N. and Oyetade, S.O. (2005). Declining Anglophone English language proficiency in Cameroon: what factors should be considered? in Chia, E. et al. (Eds.). Globalisation and the African experience: implications for language, literature and education, 64-87, Limbe: ANUCAM. 
Gardner, W.L. (2012). Towards transcultural training in phonological processes for Bantu language mother tongue translators. PhD Dissertation: published by SIL e-Books 38, Dallas: SIL International.

Herrell, A.L. and Jordan, M. (2012). 50 strategies for teaching English language learners. $4^{\text {th }}$ edition. Boston, MA: Pearson.

Hinkel, E. (2010). Integrating the Four Skills: Current and Historical Perspectives. The Oxford Handbook of Applied linguistics. Oxford, England.

Mahboob, A., Paltridge, B., Phakiti, A., Wagner, E., Starfield, S., Burns, A., Jones, R.H. and De Costa, P.I. (2016). TESOL Quarterly research guidelines. TESOL Quarterly. 50(1), 42-65.

Nforbi, E. and Siewoue, M.B. (2015). Perspectives for the competence-based approach with entry through real life situations in the teaching of English in Cameroon francophone secondary schools. In Cameroon Journal of Language Education. 1, 1-18.

Njwe, A.E.N. (2016). Language models and the teaching of English language to secondary school students in Cameroon. In World Journal of Education. 6(2), 50-67.

Nkemleke, D. and Belibi, E.P.R. (2019). Strategies for enhancing learners' language competence with special reference to Cameroon. In Syllabus Review. 8/1, 115-136.

Nkwetisama, M.C. (2012). The competency based approach to english language education and the walls between the classroom and the society in Cameroon: Pulling down the walls. In Theory and Practice in Language Studies, 2(3), 516-523. Academy publisher, Finland.

Nunan, D. (1989). Designing tasks for the communicative classroom. Cambridge, UK. Cambridge University Press.

Scarcella, R. and Oxford, R. (1992). The tapestry of language learning: The individual in the communicative classroom. Boston: Heinle \& Heinle. 


\section{Appendices}

\section{Sample examination paper no. 1}
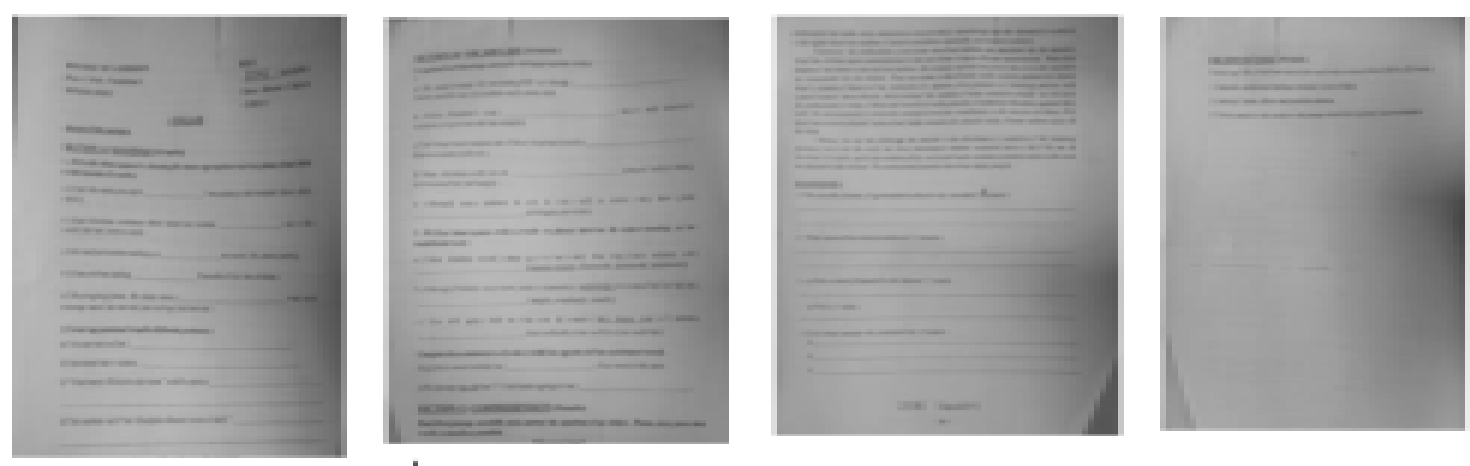

\section{Sample examination paper no. 2}
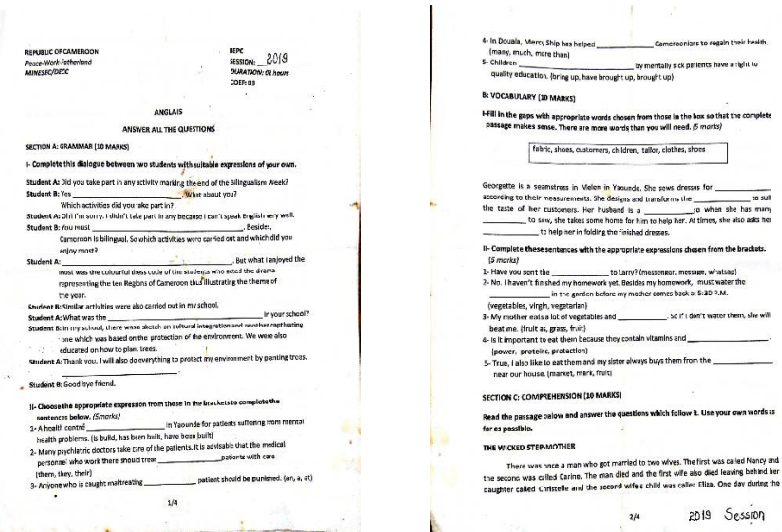

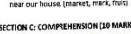

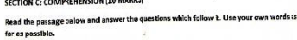

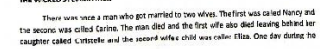

1
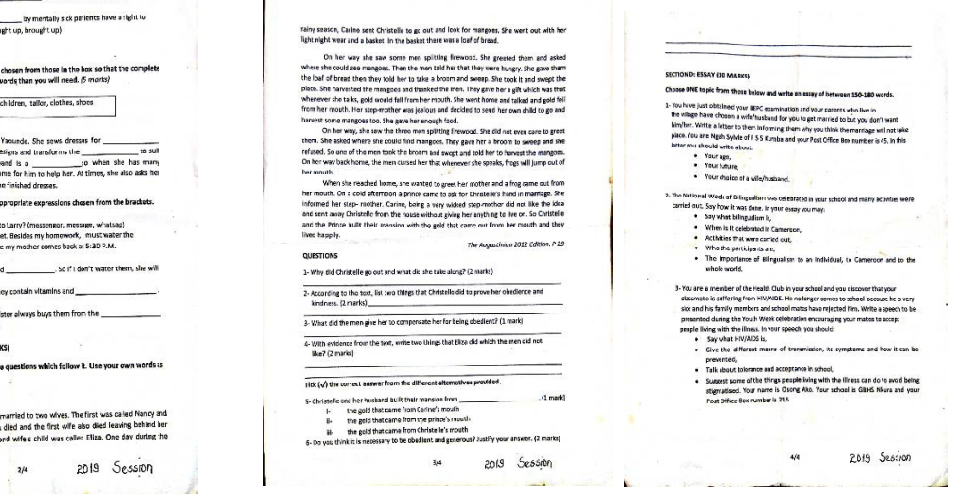

2. Sample examination paper no. 3
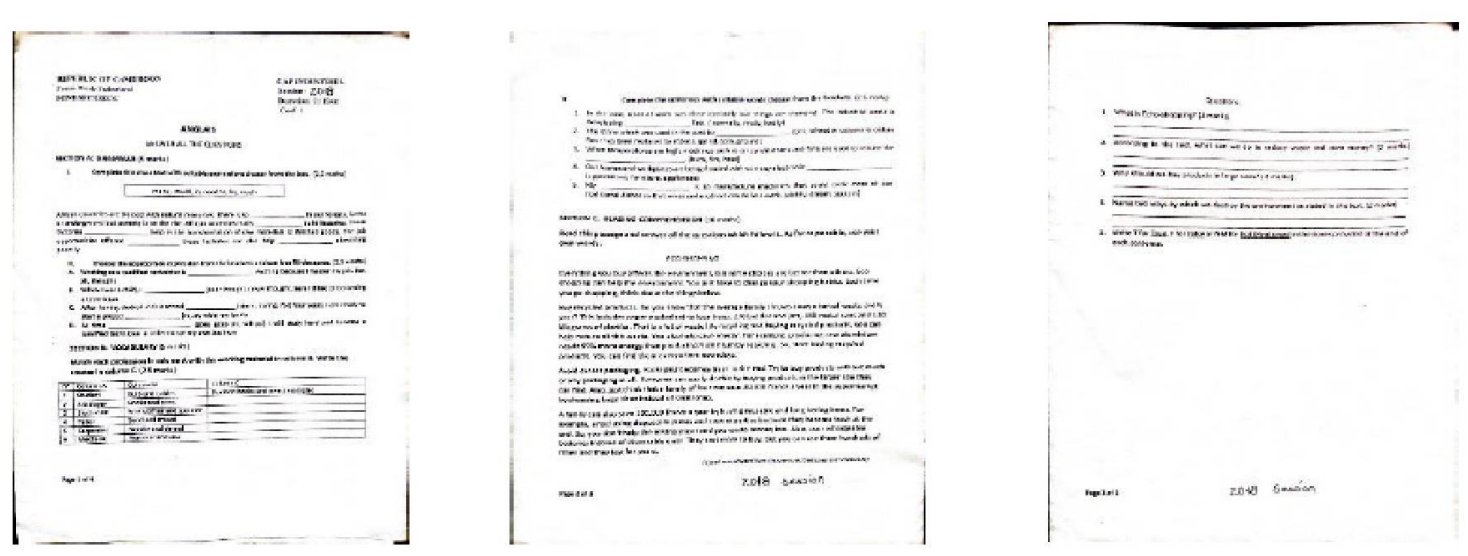

Cite this article as: Jean Paul Gaindjoung (2021). Language skills development in English through an integrated approach: The case of integrated skill instructions. International J ournal of Languages and Culture. 1(2), 23-30. doi.org/ 10.51483/ IJLC.1.2.2021.23-30. 